\title{
ACERCAMIENTO ANALÍTICO A PERSÉFONE DE HOMERO ARIDJIS
}

\author{
Carmen V. Vidaurre Arenas \\ Universidad de Guadalajara, México
}

En nuestra exposición ofreceremos algunos resultados de la aplicación de la sociocrítica al estudio del nivel mítico en Perséfone ${ }^{1}$ de Homero Aridjis. Pero antes de entrar en materia deseamos hacer una aclaración: por la naturaleza de nuestras consideraciones podría pensarse que hacemos una crítica un tanto "hereje", pero no es así: nuestras afirmaciones surgen de una serie de inquietudes que provienen de la elaboración de un diccionario de sociocrítica, lo cual nos exige ser sumamente meticulosos y exactos en las definiciones de los términos abordados.

Es innegable que al estudiar el nivel mítico de una obra hay -0 debe haber, aunque sea de modo implícito - una concepción particular del término mito y de la noción nivel mítico. De los trabajos realizados por Edmond Cros sobre algunos estudios de elementos que pueden ser incluidos en este nivel o categoría textual, en obras como La región más transparente o El Guzmán de Alfarache, por ejemplo, se deduce que Cros aplica el término mito de un modo indistinto para

1. Perséfone se publicó en 1967 , y ha sido considerado por la crítica literaria como "un poema nocturno y uno de los más largos que se han escrito en México"; otros investigadores han preferido pensar que se trata de una novela en verso. Perséfone es, ciertamente, un texto de difícil clasificación, pero también una obra de peculiar belleza y complejidad. 
referirse a un personaje, a una serie de tradiciones en relación con este, a un tópico, a una anécdota y a un tipo de estructura narrativa particular.

Cuando habla de los mitos del Génesis y de la Torre de Babel en El Ciudadano Kane, Cros entiende el mito como una estructura narrativa, como una serie de anécdotas constantes y articuladas, conjunto de rasgos y componentes que se modifican en una nueva versión. En este caso Cros es riguroso terminológicamente cuando habla de "elementos míticos" portadores de una diégesis y cuando señala que el lenguaje figurativo que caracteriza los mitos alimenta distintos estratos de la textualidad, lo cual permite aclarar el funcionamiento de la deconstrucción. Es también preciso cuando observa que el lenguaje figurativo se vierte en el texto en una nueva simbolización. Pero es menos preciso cuando estudia la tradición sobre la Edad de Oro en El Guzmán..., pues entonces emplea indiferenciadamente las designaciones mito, tópico y tema.

El término mito ha sido - hasta ahora - un concepto de definición oscilante e imprecisa, no sólo dentro del corpus metodológico del Dr. Cros, sino en el de algunos de los más importantes investigadores de los mitos (Lévi-Strauss, Mircea Eliade, Roland Barthes). Nosotros creemos conveniente distinguir claramente unos conceptos de otros, pues aunque desde la perspectiva de la sociocrítica y para los efectos de su aplicación no resulte fundamental dicha diferenciación, no debemos pasar por alto que el rigor terminológico y la precisión en las definiciones suelen ser criterios importantes en toda teoría y método científico. Esto último no impide las variaciones, aplicaciones y reconsideraciones que las prácticas obligan a hacer y que innegablemente se realizarán en toda formulación metodológica que, como la sociocrítica, esté en plena vigencia y en vital desarrollo.

No disponemos aquí del tiempo para ofrecer una visión crítica de algunas de las más valiosas definiciones que sobre el mito se han formulado en el siglo XX (este tema lo hemos desarrollado en otro trabajo). Sin embargo, hemos logrado precisar una noción de mito que es resultado del estudio de una diversidad de aspectos propios de una 
tradición mítica particular, así como consecuencia de la lectura atenta de gran variedad de tradiciones narrativas y de material teórico sobre los mitos.

Nuestro estudio se centra en la diferencias observables en tres tipos de estructuras narrativas distintas (cuento mítico, rito y mito) y nuestra propuesta parte, aunque no es del todo coincidente y luego se separa de modo visible, de los estudios morfológicos del relato, realizados por Propp, los cuales permitieron demostrar que en una diversidad de cuentos se repetía la misma estructura narrativa ${ }^{2}$.

Propp consideró que las partes del cuento eran las funciones, y por función entendió la acción de un personaje definida desde el punto de vista de su significación en el desarrollo de la intriga. Observó que una misma acción podía tener significaciones distintas y por ello corresponder a funciones diferentes ${ }^{3}$. Actos distintos podían también significar la misma cosa ${ }^{4}$. Observó que el número de funciones de los cuentos populares era limitado. También estudió los procesos de asimilación entre funciones y los casos de doble significación morfológica de una misma función. La estabilidad de la estructura localizada en los cuentos estudiados, le permitió proponer una definición de estos: "el cuento fantástico es un relato construido sobre una sucesión regular de funciones dadas, algunas de las cuales pueden ser omitidas y otras repetidas"5.

Observó también que gran cantidad de cuentos en los que había elementos fantásticos podían estar construidos según el esquema y

2. Al analizar más de un centenar de relatos, Propp notó que del mismo modo en que había en ellos elementos muy variables (los personajes y sus arributos, los escenarios y algunos de sus rasgos, etc.), con frecuencia se repetían en ellos acciones similares a las que aparecían en otros cuentos. Esto lo llevó a reducir el relato a las acciones que la narración comprendía y a observar el modo en que estos segmentos narrativos se sucedían, se parecían, se diferenciaban o se condicionaban.

3. Por ejemplo, casarse podía ser en un cuento la recompensa, en otro una prueba para obtener otra cosa deseada, en otro era el castigo por la fechoría, etc. Nos veíamos así ante elementos morfológicos dif erentes.

4. La tarea difícil podía adoptar diversas formas en distintos cuentos (cruzar un río, derrotar a un dragón, descifrar un enigma, ganar un apuesta, etc.).

5. Vladimir Propp, Estudio morfológico del cuento (México: Colofón, 1989), 149. 
aunque no precisó una terminología distintiva de este tipo de relatos, propuso las denominaciones de "cuentos míticos" para este tipo particular de narraciones. Señaló que la estructura de funciones aparecía en una serie de mitos muy antiguos y vio en ello el origen de los cuentos. No se interesó por ver si en estos casos acciones y funciones guardaban un tipo particular de relación, variable o constante $e^{6}$. Sus investigaciones serían posteriormente retomadas y enjuiciadas por Lévi-Strauss para estudiar muy diversos mitos.

Lévi-Strauss consideró que no había una notable diferencia entre mito y cuento popular, salvola mayor invariabilidad del primero. Dedicó algunas notas a estudiar las relaciones entre mitología y ritual, sin hacer diferenciaciones morfológicas claras. Otros investigadores estudiarían por igual mitos y ritos, señalando, únicamente, rasgos de tipo semántico, religioso o social como elementos distintivos entre ambos.

El estudio de la estructura de funciones resultó aplicable a muy diversos tipos discursivos, con resultados interesantes, es el caso de su aplicación al estudio de ciertos ritos, el cual permite observar que en esta estructura narrativa - pues implica un relato, como ya lo han hecho notar diversos investigadores-, acciones y funciones son siempre perfectamente coincidentes, es decir, en el rito tienen lugar siempre las mismas acciones y la significación morfológica de estas es invariable en cada realización.

Así como los ritos se distinguen claramente de los relatos estudiados por Propp, no sólo por las funciones que los estructuran, 0 por su relación con lo religioso y su papel social, hemos podido localizarotro tipo de estructuras narrativas distintas al rito y al "cuento mítico" (Propp). Se trata de estructuras en las que cierto número de acciones son constantes, pero en las que la significación de esas

6. Esta afirmación se aplica, sobre todo, a sus estudios de la morfología. Posteriormente, Vladimir Propp estudió el mito de Edipo, en un trabajo independiente del anterior y observó algunas constantes en relación con las acciones y sus rasgos, presentes tanto en cuentos de tradición oral como en mitos y relatos míticos. 
acciones cambia, se transforma en otro elemento morfológico. A este tipo de estructuras las denominamos mitos, por haberlas localizado en un importante número de relatos a los que se le ha dado esta designación, y las distinguimos de mitología, relato o cuento mítico, rito, tópico y procesos de mitificación?.

En este trabajo nos limitamos al estudio de algunos elementos propios del nivel mítico en el poema de Homero Aridjis, Perséfone. A partir de las consideraciones anteriores podemos decir que en la obra de Homero Aridjis no encontramos, propiamente, un mito sino la presencia de una serie de elementos míticos que proceden de fuentes diversas y que son portadores no sólo de una diégesis sino de una plusvalía semántica que será alterada y reorganizada en la nueva versión.

Es sabido que Perséfone es el nombre de un personaje que interviene en varios mitos. El más difundido es aquel en el que la antigua potencia aparece como hija de Deméter. A tal punto es conocida esta tradición que James Frazer no hace referencia a ninguna otra e ignora los diversos textos en los que aparece el personaje, para únicamente citar el Himno a Deméter atribuido a Homero. Sin embargo, a esta referencia habría que agregar, por lo menos dos cantos de la Odisea (V, X y XI); y los cantos II, V, IX y XI de la Ilíada, así como las referencias a Perséfone que aparecen en las obras de Esquilo, Eurípides, Sófocles y Aristófanes, para sólo hacer mención de las tradiciones literarias griegas, sin mencionar la derivada tradición latina ${ }^{8}$.

7. Pues a la mitología le restituimos su sentido de corpus narrativo en el que, mediante la conjunción de diversos relatos sobre dioses y/o héroes (que pueden adquirir el carácter de mitos, pueden tener la estructura de cuentos míticos, fábulas, leyendas, etc.), se explica el origen de un pueblo, de una civilización, o incluso de la humanidad. La mitología tiene un carácter no sólo ejemplar sino explicativo de una serie de concepciones y prácticas ligadas con frecuencia a lo religioso. Mientras que por cuento mítico distinguimos las estructuras narrativas estudiadas por Vladimir Propp y aquellas otras que cumplen con la mayoría de las funciones por él localizadas.

8. De Natura Deorum de Cicerón, Historia Natural de Plinio y los Anales de Tácito. 
Noes la estructura narrativa que cita Frazer la principal tradición que interviene en el texto contemporáneo. La obra misma nos proporciona una serie de indicios que nos conducen a la tradición homérica en la que participan Tiresias y Ulises, la cual se entremezcla con otros materiales intertextuales, entre los que figura la Divina Comedia de Dante.

En el canto XI de la Odisea, el protagonista narra la evocación de los muertos que se ve obligado a realizar para saber qué es lo más adecuado a sus propósitos. Según la rapsodia, cuando las tinieblas ocupan todos los caminos, Ulises arriba a la ciudad de los Cimerios y en un lugar determinado, que ha sido señalado por Circe, desenvaina su espada, abre un hoyo en la tierra, hace libación a los muertos, suplica y ofrece sacrificio, para congregar las psiques de los difuntos. Sombras de mujeres, jóvenes, ancianos y guerreros se muestran entonces y se agitan alrededor. Ulises se entrevista con los muertos (Espénor, Tiresias, Anticlea, Alcínoo, Aquiles...), los oye hablar de su pasado y preguntar por el presente que desconocen. Otros de los personajes sólo son vistos y descritos a distancia. La visión acaba cuando Ulises expresa su temor a que Perséfone le muestre la cabeza de Gorgona-Medusa y de ese modo le cause la muerte.

En la nueva versión del mito en la obra de Aridjis, podemos observar una serie de constantes y otra de variables visibles: como en el fragmento del poema épico griego, en el poema narrativo de Aridjis, la instancia enunciativa posee características estables. En ambos casos se da un proceso de focalización desde la perspectiva interiorizante del protagonista que se dirige a un locutor externo, no expreso en el caso del texto del autor mexicano.

Se conservan en la obra de Aridjis abundantes referencias a la noche. En el ámbito de la anécdota se refieren los encuentros del protagonista con un conjunto de seres que se localizan habitualmente en un lugar connotado por una serie de rasgos que lo vuelven similar al Hades, pues se trata de un espacio subterráneo, oscuro, un "abismo horizontal" (150). Esos seres que miran "desde una existencia que ha 
pasado de largo o que todavía no llega" $(136)^{9}$, son seres que se relacionan, se muestran y hablan con el personaje, quien los observa actuar, son seres que están "enterrados sobre la superficie" (Ídem).

Los encuentros adquieren el carácter de verdaderas visiones ${ }^{10}$, en las que el personaje convive con multitudes que son "muertos asombrados" (291). Como en el caso de la Odisea, el protagonista participa de fragmentos de "existencias" y de historias, y esto le of rece "iluminaciones", tomas de conciencia y le permite hacer valoraciones. Como en el canto de la Odisea, al protagonista se acercan hombres y mujeres, hablando de gentes que este conoce (136).

Las variantes son, sin embargo, más numerosas que las semejanzas: el Hades se ha convertido, en esta nueva versión, en un "antro", en un prostíbulo. El lugar que correspondería al señor del mundo subterráneo, Hades, es desempeñado por "el dueño del antro", que "gobierna el elemento de servicio": "casi oculto para los clientes y para aquellos que no esperan de él ningún consentimiento" (137). En lugar de la libación y el sacrificio, lo que convoca a la multitud de sombras es la promesa de placer sexual, "el misterio de la droga y la cópula" (147). Los muertos y sus sombras se han convertido en los clientes del "antro" y prostitutas.

En la iconografía antigua, tanto Deméter como Perséfone son representadas con una antorcha en cada mano, sentadas en un trono; en la obra de Homero Aridjis, Perséfone está "sentada en un hombre; con una copa en la mano que parece cáliz; con un cinturón en la otra que parece bastón" (135).

En esta deconstrucción que opera sobre una forma, sobre un sintagma figurativo, se expone una problemática sobre el ser y la apariencia, al mismo tiempo que tiene lugar un proceso de erotización en el que no están ausentes ciertas connotaciones sadomasoquistas ni

9. $\quad$ No podemos pasar por alto que el Hades era el lugar al que se dirigían los muertos para reen carnar o permanecer en la muerte y dueños de su memoria.

10. No en vano el texto concluye con las frases: "He visto [...]; Y lo (jue vi no lo vi yo, simo (1)r(u)" (291). 
un discurso ritual-religioso, convocado por la referencia al "cáliz". El bastón a que se hace referencia opera como un signo pluriacentuado, por medio del cual la figura femenina es connotada por rasgos de autoridad y poder (masculinos), pero también de ancianidad y ceguera, connotaciones que dentro de la tradición implicada, el bastón suele portar.

El persona je de Perséfone, aparece así como relacionado con el ciego Tiresias, el ciego vidente. Esta asimilación entre uno y otro personaje se expondrá en diversos momentos de la obra y de variadas formas. La ausencia total en el texto de la figura de la madre, en este caso de Deméter, expone una nueva y otra relación familiar a la que se implica en el mito antiguo sobre la madre de Perséfone. En esta nueva relación, las figuras de la autoridad familiar y las de una madre de celosa entrega están ausentes.

Aunque en la obra de Aridjis aparecen jóvenes, mujeres y ancianos, la figura de los guerreros está ausente; en su lugar aparecen vendedores, empleados y un grupo de personajes que: "[...] no son hombres ni mujeres, vestidos de virilidad contestan femeninamente, ceñidas de corsets son más que hombres" (158).

Otros personajes un tanto ajenos a la tradición sobre Perséfone, aunque no totalmente desligados de ella, aparecen también en la obra, observando rasgos particulares: las potencias femeninas trinitarias - $\tan$ frecuentes en la tradición griega - (Grayas, Gorgonas, Gracias, etc.) se han convertido en "tres lesbianas" (139); mientras que el personaje de Caronte parece convocado en la figura de una mujer: "Muchacha de caderas anchas y espesas pasa junto a mí [...]/Mueve los brazos por el aire con la torpeza de aquel que está remando" (152). La figura de Cerbero se ha transformado en un ser colectivo: "Lentas [...] maliciosos" (162). El trabajador doméstico aparece identificado con lo animal en esta sustitución.

El personaje protagonista es un muchacho, en lugar de un hombre que ha pasado largos años lejos de su familia y quiere regresar cuando ya es un hombre de cabellos canos. En la reelaboración de los materiales preconstruidos podemos observar que se pone en juego un texto semiótico en el que se oponen juventud/vejez. 
El discurso económico-comercial contamina el discurso de la tradición mítica y remodela tanto a los personajes y sus rasgos, como las características del espacio y de las relaciones que se establecen entre algunos de los actantes.

Un proceso de erotización de los materiales preconstruidos, palpable en la sustitución del alimento y la bebida por la cópula sexual y la droga, se hace presente a lo largo de toda la obra y se relaciona con un texto semiótico en el que se oponen y se sustituyen constantemente lo masculino y lo femenino, para dar lugar a un proceso de androginia.

Esos pocos elementos que hemos enumerado nos permiten ya observarque en las deconstrucciones aparecen estructuras que corresponden a algunas de las estructuras ideológicas que marcaron en México la década de 1965-1975. Me refiero, por ejemplo, a la androginia que se manif estó no sólo en la moda unisex, sino en todos los nuevos papeles y prácticas sociales adoptados por los jóvenes de estas generaciones, en las que tuvo lugar también la llamada "liberación sexual" y se expuso una marcada erotización de las prácticas vitales, manifiesta -incluso- en los discursos comerciales de la época ${ }^{11}$.

Esa década también estuvo muy marcada por la oposición entre jóvenes/viejos: recordaremos expresiones tales como "viva la chaviza, muera la momiza", que se repetían a gritos entre los muchachos de la época.

Con respecto a la asimilación que se hace en el texto, entre el trabajador doméstico y el animal, podemos notar que en el habla coloquial de México, es común la referencia a la servidumbre, a la empleada doméstica, con la designación —cada día menos frecuente, por fortuna- de "gata".

Aunque nuestras observaciones han sido rápidas y esquemáticas, ilustran el modo en que el estudio de los materiales míticos reporta de un modo privilegiado los cambios en las estructuras ideológicas.

11. Recordaremos las duras críticas que la sociología marxista y las feministas hicieron a uso del sexo y de la figura femenina como objeto de consumo. 